\title{
From Parrots to Puppet Masters: Fostering Creative and Authentic Language Use with Online Tools
}

\author{
JOHN MILTON
}

\section{Problems in Foreign Language Education}

The teaching and learning of English as an international - albeit foreignlanguage in SE Asia are beleaguered by a number of problems, which in a general sense are faced in the teaching and learning of other types of knowledge and skills as well. One of the most frequently discussed is the force-fed pedagogy in which many teachers and students find themselves trapped (Zeng, 1999). Many educators believe that 'teaching to the exam', which is common in public and private institutions in SE Asia, encourages imitative practices by dampening students' desire and ability to learn (e.g. Paris, 1995). This problem is related to the often-observed tendency toward an imitative rather than a creative approach to learning in SE Asian classrooms (Cheng, 1999).

Narrowly focused teaching practices dominate the curriculum from primary to tertiary and are rationalized by the face validity that norm-referenced standardized assessment promises. An unhappy outcome is that many students spend the bulk of their education memorizing formulae easily parroted in examinations, but inadequate for life outside the classroom. In the case of foreign language learning, stock phrases are often made to substitute for grammatical and communicative competence in the target language. The foreign language (L2) that students acquire is often a constrained and unnatural version of the language they need for academic, professional, business or social communication (see Milton, 2001). This situation is further exaggerated in English as a Foreign Language (EFL) teaching by a dearth of proficient teachers, insufficient time and resources to develop effective learning opportunities, and lack of coordination of the substantial efforts made by dedicated teachers. 


\section{A Distributed Model for Teaching and Learning EFL}

Where Internet (especially broadband) access and computer ownership are common, making resources available online would seem to be one way of partially addressing these problems. In principle it is possible to coordinate best practices through a distributed model of delivery while allowing considerable choice and flexibility on the part of students and teachers. It has long been realized that a curriculum incorporating online elements can provide greatly enhanced directed instruction as well as more opportunities for autonomous exploration and discovery (Barnett, 1993). The need to meet local standards can also be addressed more efficiently, while wasted time and resources can be reduced, and teachers and students can be freed to engage in collaborative as well as individualized creative activities. Implementing these possibilities so that technology helps reform instruction and learning, rather than simply amplifying bad pedagogy, is both a design and social challenge. In this chapter I will briefly illustrate high interest interactive activities that can be aimed at the specific interlanguage problems of L1 speakers; useful pedagogical tools that can be made widely accessible; and technically enhanced opportunities for communication among students and between teachers and students.

I will first outline the rationale for Web-based EFL resources and then describe four tools that lend themselves to progressive approaches to broader learning opportunities. I have incorporated these tools into an online course development system that supports several online EFL courses aimed at various groups of learners. These include full-time secondary school students, undergraduates, post-graduate students enrolling in MBA courses, and continuing education students. They are mainly Chinese (Cantonese and Putonghua) speakers at a wide range of English proficiency levels, needing to acquire a broad array of receptive and productive English skills.

\section{Parameters for an Online EFL Course System}

Before attempting to design anything new, I set about looking for an online content development and management system to assist materials developers and teachers to create engaging and meaningful learning activities. My criteria were that this system should support learning that follows generally agreed educational principles and that meet pressing logistic needs by:

- appealing to a wide range of learner proficiencies and interests by providing quality, individualized instruction; 
- motivating low-proficiency students to find intrinsic uses for the language;

- ensuring a coherent, planned and progressive curriculum based on SLA theory, while also providing opportunities for self-discovery, participation, creativity and the pursuit of individual learning paths (i.e. the type of quality assurance guidelines outlined by Alley \& Jansak, 2001);

- enabling and encouraging teachers to act more often as mentors, and less often as pedagogues;

- enabling a transparent system of student and teacher accountability by integrating intrinsic, criterion-referenced and performanceoriented formative assessment into the learning process, thereby minimizing the need for extrinsic, norm-referenced summative assessment;

- providing timely and reliable reporting to the teacher, allowing for reliable, consistent grading, and timely and effective feedback to learners; and

- permitting ongoing evaluation of the content and methodologies by the students and teachers.

The commercial course delivery systems I evaluated give reasonably good support for the management of students and materials and allow basic information delivery, assessment and text-based communication. However, none seemed fully to exploit the possibilities suggested above. The systems do not incorporate tools or resources that accommodate individual learners by making the $\mathrm{L} 2$ more readily available than it is possible through print resources, nor do they explicitly include techniques for encouraging the creative or authentic use of language. Although new forms of Internet communication and interaction continue to be developed, these new technologies often take considerable time to be integrated into commercial course delivery systems, and new technologies cannot be easily incorporated into most learning platforms on an ad hoc basis. Also, most systems leave much to be desired in the ease with which content can be authored (see Jensen, 2003, for a detailed critique on course management systems). I was disappointed to find that, despite the promise of Internet technology, no ready-made content delivery system seemed to offer the range of activity types and tools that meet the Web's potential to create and deliver courses for dynamic language learning.

However, database-driven Internet technologies have matured to the extent that it is technically and economically feasible to develop original, customizable systems that can be used to create, deliver and manage appropriate online tools and content directed at a specific discipline such as 
language learning. I decided to take this route, and with a small team of students, developed a course delivery and student management system specifically to manage language learning. The chief advantage of this custom-built system is that it incorporates a number of tools and activity types designed for language learning, and new technologies can easily be integrated into the central management architecture as they are needed or become available. To date over 300 activities that take advantage of the language learning tools described below have been written for this system. These include objective, automatically graded tasks (such as multiple choice, gap fill, drag-and-drop, matching, etc.) and productive, subjectively evaluated activities for which computer-enhanced feedback can be provided by the teacher. In the remainder of this chapter I will describe four tools aimed at providing practice in speaking the L2, making L2 lexis, structures and texts more accessible, improving teacher feedback and promoting creative use of the L2.

\section{Targeting Oral Fluency: Asynchronous Voice Messaging}

Graduates from SE Asian classrooms are often observed to have low spoken English fluency. This is not surprising since most students in these contexts have little perceived opportunity to use the target language in their daily lives: in many cases little communication takes place in English outside (and often inside) traditional classrooms. Although the communicative approach, with its emphasis on spoken language, is enshrined in teacher training courses, there is often little interaction in spoken English among students or between students and their teachers, and spoken English is rarely assessed. One of the tools incorporated into the online course system introduced above facilitates and motivates L2 speech by enabling students to hold conversations via the Web and by making it easy for teachers to promote and monitor these conversations. ${ }^{1}$

Teachers can leave recorded messages to encourage discussions and they can elicit responses that focus on specific skills (e.g. pronunciation and intonation), or that model various spoken business, academic and social situations. Full-time students are required, in groups of two or three, to schedule regular times to hold and record conversations. Continuing education students have the option to log on at any time over the course of a week to comment on weekly themes. Messages are posted to Web pages reserved for each pair or group of students and their teacher, and are archived so they can be accessed as a threaded oral discussion forum. A similar procedure has been successfully practised in Japan for a number of years using tape recorders (Schneider, 1997). Despite the obvious limitations in having students of the same L1 carry on a conversation in an L2, 
those using the technique in Japan have reported considerable evidence of learners encouraging and teaching one another (Kluge \& Taylor, 2000). I have found that students take to this activity more eagerly than they do more conventional academic tasks, that interaction among learners tends more often to rely on the L2 than in classroom situations, and that particular skills (such as telephone language) can be easily modeled. Many of the technical and procedural difficulties of using tape recorders are overcome by this Web-based conversation practice. Although detailed monitoring and interaction by the teacher is time-intensive and not always possible, occasional teacher participation and feedback appears effective in encouraging fluency practice. Most learners report increased confidence after a few weeks of conversation practice, and their increased ease with the language has led many of my students to report a newly discovered relevance for English.

Depending on their goals and needs, teachers and learners can concentrate on this type of fluency practice. They can also access online references and activities directed at lexical acquisition and improved accuracy, as described below.

\section{Online Data-driven Language Learning}

Among the references available to learners in this system is a discovery-based lexical lookup tool (Word Neighbors). I designed this tool based loosely on the linguistic principles described by Sinclair (1991) and on the concordancing techniques outlined by Johns and King (1991). It allows the lookup (including the use of wild cards ${ }^{2}$ ) of immediate contexts of any selected word or phrase in various large corpora from a right-mouse button context menu. This method provides a way of enabling learners to become self-reliant in discovering the collocational properties of the language. Students are encouraged to use this tool in a number of ways, such as in the completion of autonomous logged activities which assist with proofreading skills and vocabulary acquisition. Some of these activities are illustrated in Figure 14.1. Students are also encouraged to use it when they write, as I illustrate in the next section. This tool remains available to students as a writer's aid after they have completed their course and can be called directly from their word processor.

\section{Providing Feedback on Student Writing}

Although the oral approach is emphasized in current theories of language pedagogy, EFL curricula and examinations in schools and universities tend to concentrate on written accuracy (often at the sentence level), and 'error-free' writing is a common preoccupation at school and on 
the job. However, there is little agreement on what form teacher feedback to student writing should take or at what level of written expression (sentence or text) it should be aimed. In fact, possibly no issue is more contentious in language teaching than the debate over how to respond to students' written work. Even when process-writing methods are adopted, the procedure for making comments is often frustrating, and the usefulness of our remarks is often questionable. Teachers usually have few, if any, objective empirical criteria for commenting on students' interlanguage, or by which to check progress and arrive at justifiable grades. The most conscientious teachers often find that detailed and copious comments seem not to result in measurable difference in students' writing. There is also the danger that when our comments are attended to, they run the risk of forcing students into conservative strategies of error avoidance, since they usually focus on errors of commission rather than errors of omission (Perkins, 1983). Nevertheless, detailed response to students' written work is viewed as a critical part of our job, and students say that they value and expect it (Ferris, 1995). This leaves many teachers overwhelmed by the volume of correction that students appear to need, or that the curriculum mandates. Yet, this demand continues relentlessly, despite the lack of consistency and accuracy in our feedback (Biggs \& Telfer, 1987), and regardless of its less than entirely desirable consequences.

Students rarely have access to the didactic or procedural resources they need to correct the errors we are able to identify, or to choose alternative L2 structures and lexis that are authentic and textually relevant. They are often not held accountable for proofreading or correcting their work, or for demonstrating improvement from one assignment, semester or course to another. Instructors of mainstream courses frequently consider commenting on the language of written assignments a waste of time or none of their concern, with the result that students can spend three or four years at university without receiving much useful feedback on their writing or any evidence of the relevance of effective writing skills. They may in fact not write very much at all, since assessment in many subjects at university is largely by multiple-choice responses.

My approach to this situation has been, first, to collect a large corpus (several million words) of the writing of my students (Cantonese speakers), and to compare this with the writing of native speakers of the same age and educational level so as to identify misuse, as well as 'overuse' and 'underuse' of selected structural, lexical and discourse features (Milton, 2001). Based on this analysis, I maintain an extensive online grammar/ writing guide (currently about 1000 pages). This guide contrasts standard and nonstandard forms and includes quizzes so that students can focus on and practise problems specific to the writing of speakers of Chinese. 

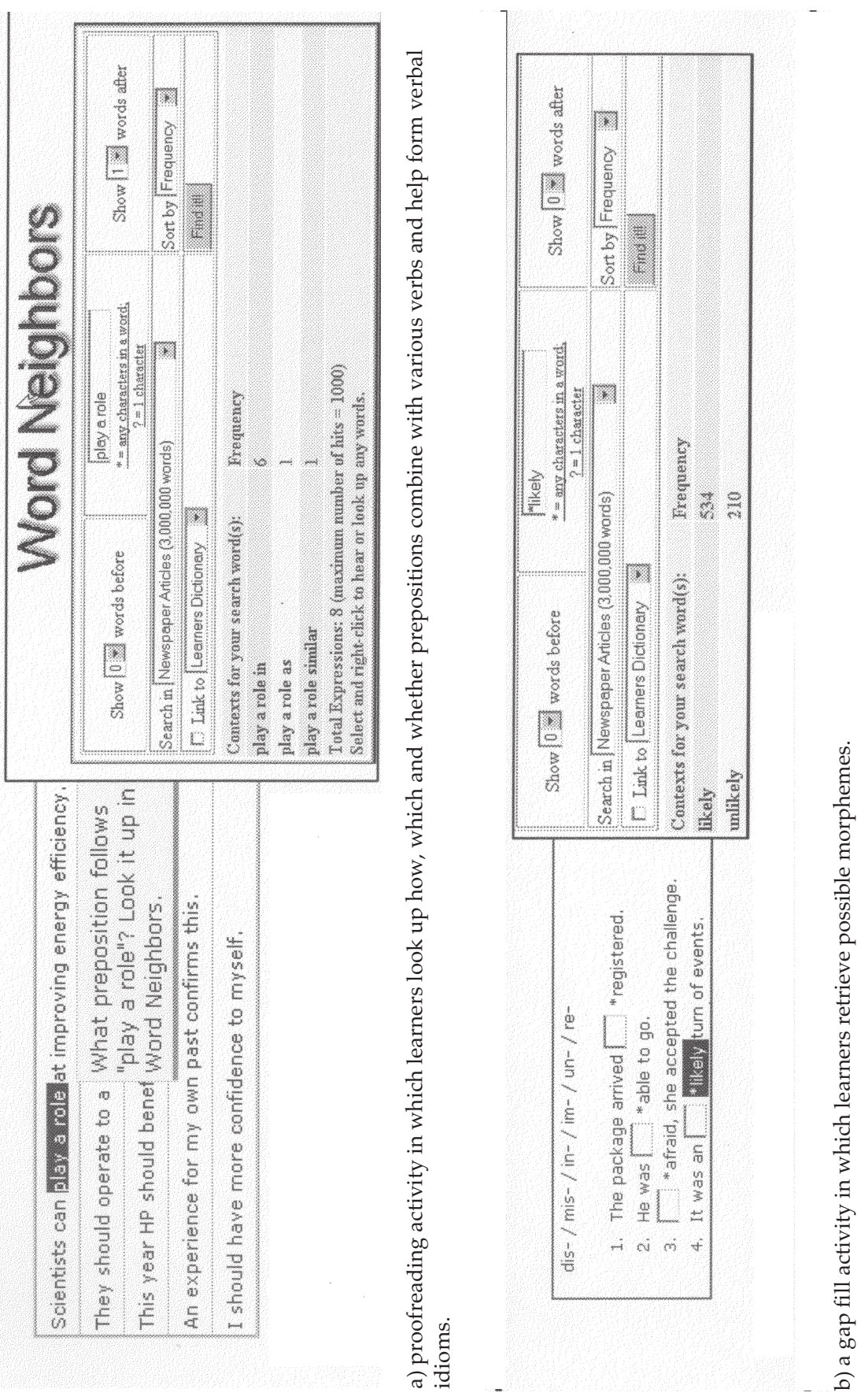


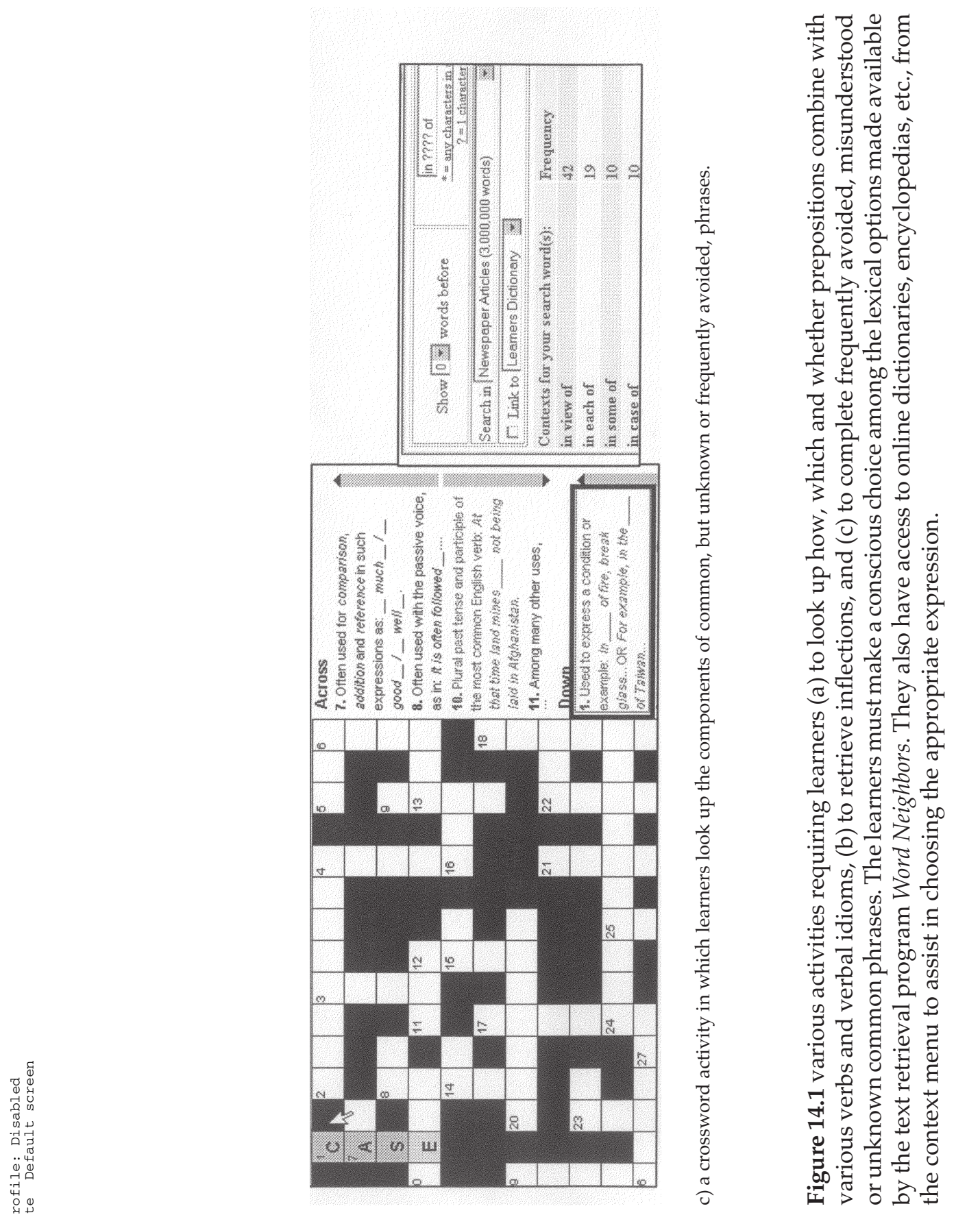


Next, I designed a marking tool (Mark My Words) which teachers can use to insert comments in students' electronic documents. This marking tool can be used to point to the online guide and to other references (such as Word Neighbors, described above). Students (who have access to these online references when they write) submit their documents to a Web page 'drop box'. Teachers then retrieve the documents, insert pre-defined and individualized comments based on what the students are expected to have mastered, and post the documents back to the Web (often within the same day assignments are submitted). Students can be requested to resubmit their work if substantial changes are needed, based on these comments. Comprehensive pre-defined comments can be inserted in written work in about $20 \%$ of the time it takes to mark up paper submissions. Tedious individualized correction is minimized since most of the errors made by students of the same L1 are recurrent, and the students are held responsible for using deductive processes, such as the Word Neighbors text retrieval program, to correct their errors. Figure 14.2 illustrates a pre-defined comment inserted in a student document and some of the online resources this procedure makes available. Teachers can also use the normal commenting and tracking features of their word processor to make individualized remarks if necessary (these remarks can then be archived or incorporated into the online guide).

\section{Online Role Plays}

I have so far demonstrated online tools and activities that can provide learners with oral fluency practice, discovery-based lexical acquisition and enhanced feedback on their writing. In this section I will describe a tool aimed at motivating the creative use of language through the scripting of spoken English. This tool can also be used as a means to promote both fluency and accuracy. Since it is perhaps the most novel of the techniques I describe in this paper, I will first dwell in some detail on the rationale for its use as a language acquisition device.

Oscar Wilde observed that 'Education is an admirable thing. But it is well to remember from time to time that nothing that is worth knowing can be taught' (1913: 104). How to make known the unteachable may in some sense be answered by Muriel Rukeyser's 1960 remark that 'The universe is made of stories, not of atoms'. Encouraging the language learner to adopt the role of narrator seems particularly relevant as a means of acquiring language skills. Teachers across disciplines often encourage protected immersion in the L2 through role-playing activities, usually face-to-face, but more recently at a distance (e.g. using 'virtual worlds' such as MUDs). The benefits of role-playing for generalized educational settings are 


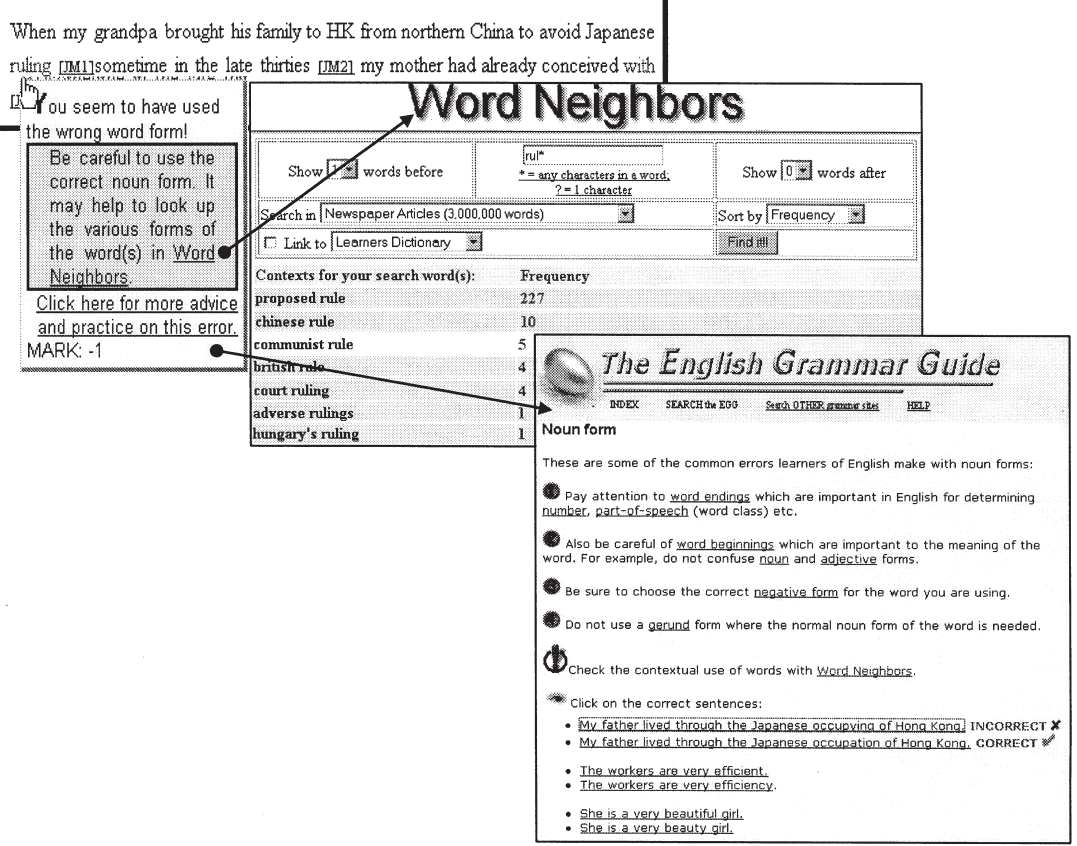

Figure 14.2 A student submits a written assignment to the Web site; the teacher then opens the document and inserts comments using the marking tool. The student sees relevant popup comments, from which Word Neighbors and other references, including the English Grammar Guide can be accessed.

detailed in Jones (1985), and specifically for language learning in Ladousse (1987), Crookall and Oxford (1990) and Bambrough (1994).

Several theorists recommend the use of dramatization, 'actualization' and narrative techniques for effective learning, regardless of the age of the learners (e.g. Oller, 1993). Scarcella and Crookall (1990) also review research to show how simulation facilitates second language acquisition by giving students the opportunity to try out new language in a safe environment. The learning theories they discuss claim that learners acquire language when:

- they are exposed to large quantities of comprehensible input through being engaged in genuine communication as part of the roles assigned to characters; 
- they are actively involved in worthwhile, absorbing interaction that tends to make students forget they are learning a new language; and

- they experience positive feelings and attitudes.

More recent studies have investigated the effects of students' participation in multimedia narratives on language learning and have also found positive results (e.g. in lexical gains - Duquette et al., 1998; Nikolova, 2002 and in a greater variety of rhetorical structures and increased audience awareness - Warschauer, 1999). These studies claim that the dramatization of 'real life' problems helps students develop both their critical thinking and language-related problem solving skills. Role-playing appears to be a useful language acquisition activity in that it raises the L2 from mere examination fodder to the status of a vehicle for the realization of social transactions.

This 'scripting tool' which I designed and incorporated into the course delivery system allows students to create animated role plays online. Students manipulate characters on screen, assign them movements and gestures and write dialogue that is synthesized and 'spoken' by the characters, whose mouths move to match the dialogue. This tool uses technology ('MS Agent') that was originally developed to give a social dimension to the computer interface (Ryokai et al., 2003). ${ }^{3}$ Figure 14.3 illustrates the scripting tool and an example of an animated play, with feedback using the marking tool described above. Of course, teachers can dispense with detailed lexical or structural feedback, and concentrate instead on the pragmatics of the learners' discourse.

The text-to-speech capability of this technology allows students to listen to their dialogues (or any other text on a Web page) rendered with standard American or British synthesized pronunciation. The current state of development in freely available text-to-speech engines is such that the synthesized suprasegmentals (e.g. stress, rhythm and intonation) are not entirely human, but the students who have taken the courses (almost 1000 to date) rarely complain about the quality of the synthetic voices. Indeed, they report finding the relatively high accuracy in pronunciation useful (the voice synthesis can be replaced by a recording of a human voice if the student or teacher wishes, e.g. where prosodic modeling is crucial).

The scripting tool based on this technology gives teachers and students the opportunity to script and edit conversational dialogue, thereby bringing another dimension to the presentation of, practice with and feedback on oral language. Since teachers have access to the written script, they can supply feedback on the accuracy, fluency and effectiveness of the students' dialogues, using the marking tool described in the previous section of this paper. This makes it possible to provide more detailed and 


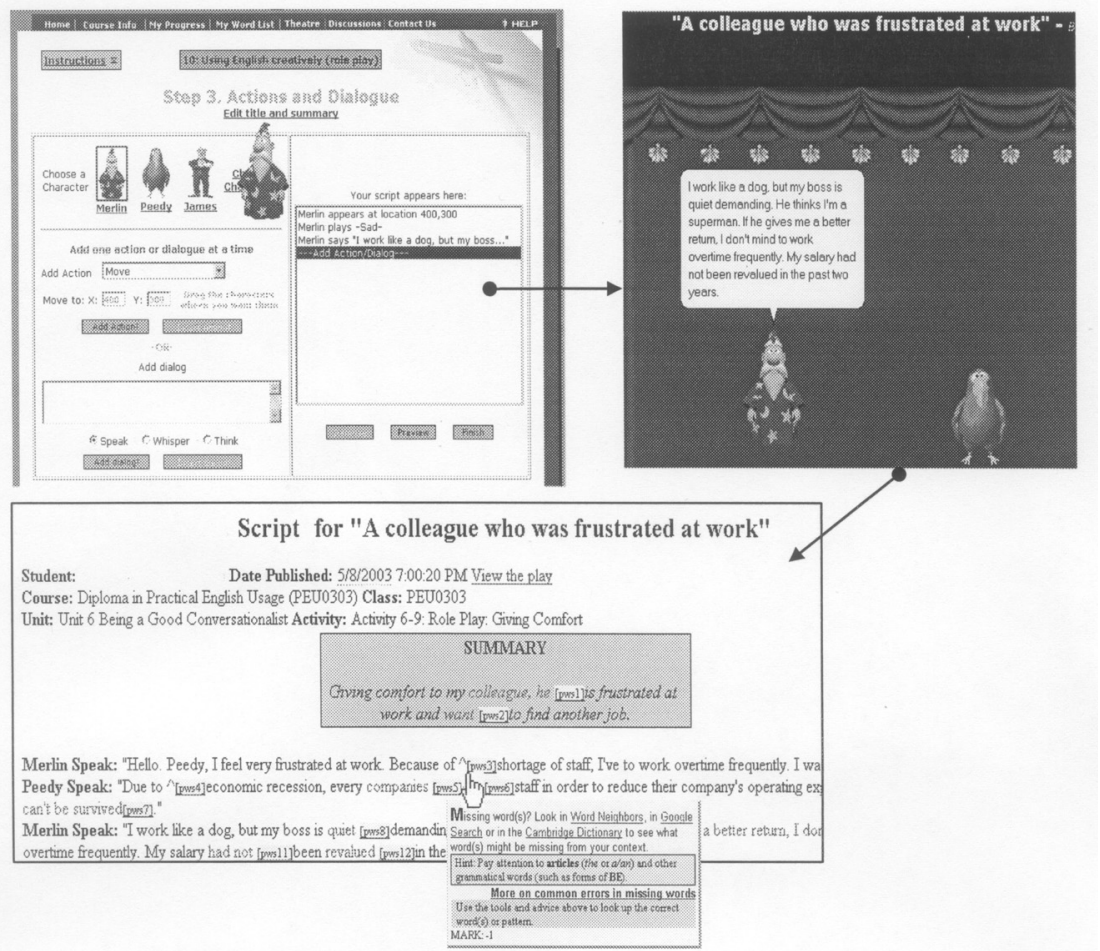

Figure 14.3 A scripting tool that allows the creation and publishing of plays on the Web: the resulting play uses animated agents and synthesized speech. Teachers and students assign behaviors and dialogue to the animations according to the focus of a unit (e.g. language points, social themes, etc.). The Mark My Words marking tool can be used to comment on the script, and the student has several references available to correct the script.

non-intrusive comments on the structure, lexis and pragmatics of the students' spoken language than is normally possible.

As well as being a useful vehicle for practice in conversational language devices, this tool gives learners the chance to demonstrate 'higher order' linguistic skills such as the pragmatic devices necessary for developing a narration, resolving a conflict, conducting a negotiation, etc. Before creating a play, the students' attention is focused through preparatory activities on commonly avoided, misused or overused language devices. The role-playing activity gives students the opportunity to be creative, to learn how to express the values of another culture, and to develop practical language strategies for handling business and social communication. 
Those who are normally shy to speak spontaneously in a classroom out of concern for their imperfect English appreciate the opportunity to practise the language in this context. This method of producing scripted speech also appears less prone to plagiarism than conventional writing assignments. The dialogues tend to be unique and personalized possibly because the activity is not associated with academic assessment and right/wrong answers, as is often the case with standard writing activities.

This role-play activity (normally assigned several times throughout a course) enables students to work collaboratively at a distance. However, while role-playing may be an ideal participatory exercise, this ideal cannot be fully realized if students find it difficult to schedule meetings (either in person or online) in order to co-design plays. It is interesting, in light of the importance attached to collaborative activities by various learning theories, that the working students who have taken the courses in a continuing education context usually choose not to collaborate with other students in writing their role-plays. They do, however, often work with family members in designing and scripting the plays. Even when they write their plays alone, they socialize through the public production of the scenarios, by giving and receiving classmates' feedback, and through the virtual relationships they establish among the animated characters. Several of the 'higher-order' outcomes that are claimed for team-based role-playing activities are also possible in the creation of individually written role-plays, such as increased confidence in language production, heightened discriminatory skills, and the sheer fun that comes from the act of personal expression and creation. Collaborative elements can be retained even when students choose not to produce the plays collaboratively. In addition to commenting on and grading each other's plays (by assigning 'stars'), students often spontaneously continue narrative lines from their classmate's plays in their own scenarios.

Fellow students as well as the teacher supply feedback to each play, and students can re-write their scripts. Care is taken to make the purpose and structure of the role-plays clear, since many students are more accustomed to conventional essay assignments than they are to communicative methods of evaluation (see Li (1999) for a discussion of the mismatch between student expectations for teacher-led instruction and the participatory methods often preferred by Western-educated teachers).

Using this technique the course developer and teachers can also present the learners with a wide range of language features in communicative contexts, including problematic or unknown grammatical structures and lexis. Scripts written by learners often make use of surprisingly authentic dialogue. Students more easily adopt opposing points of view than when they write in essay form, and they seem to make more efforts at modeling 
challenging encounters and problematic language, which they normally avoid in formal writing. The language difficulties they naturally meet provide relevant teaching opportunities, and are evidence of involvement in genuine communicative acts, rather than the mere completion of academic exercises in error avoidance. This role-playing exercise is one of the most popular of the activities made available by the online course system: almost all students find this activity 'very interesting', and most mention it as one of their favorite activities.

\section{Conclusion}

The system outlined in this chapter allows language teachers and course writers to take advantage of ongoing advances in Internet technology to deliver principled language instruction. It makes possible and encourages independence and life-long learning skills supported by access to tools that provide oral fluency practice, that expose and explain the characteristics of authentic English texts, that enable the teacher to provide timely and relevant feedback, and that encourage the creative use of the L2. The components of this system seek to address cognitive, affective and social learning needs and to allow students to pursue their own language learning goals free of many of the logistic limitations of the classroom. However, all students have the option of attending face-to-face tutorials as well. These online activities are not meant to replace the classroom experience, but they can extend and enhance it.

The specific modalities highlighted in this chapter combine Internet delivery with online voice chat, free-text retrieval, computer animation and speech technology to enable language learners to experiment with the second language in simulated and supported contexts and to enable teachers to track the students' success. Various functional thematic contexts (telephone skills, encouraging and criticizing, the language of negotiation, etc.) are addressed in the courses developed on this system. Relevant grammar, lexis and discourse features, along with the prosodic features of spoken language (e.g. stress, rhythm, intonation and pronunciation), are presented to and practised by students through a variety of high-interest interactive activities. Spoken and written input and feedback are based on extensive research (Milton, 2001) into the student's interlanguage, and the resources made available are more accessible, authentic and copious than is normally possible in the confines of a classroom. Approaches such as those outlined in this chapter may help liberate learners from some of the wooden limitations of traditional pedagogy, and may help free teachers from having to pull the strings. ${ }^{4} \mathrm{D}>$ 


\section{Acknowledges}

The author wishes to acknowledge the support of the HKUST College of Lifelong Learning (http://www.cl3.ust.hk/), and the HKUST Language Centre (http:/ / lc.ust.hk/), who provided assistance in administrating and teaching the courses described in this chapter.

\section{Notes}

1. This program was developed in collaboration with a colleague at my university and is freely available at http:/ / www.cs.ust.hk/gong/. A commercial program that has many of the same features is available at http: / / www.wimba.com.

2. These wild cards consist of an asterisk to represent any number of characters in one word and a question mark to represent one character (e.g. 'in???? of' = in view of, in each of, in some of, in case of . . . ; 'match" ${ }^{*}$ match, matches, matched, matching, matchmaking, matchless).

3. The technology I used to develop the scripting tool is described at http:// www.microsoft.com/msagent/ default.asp.

4. Some measure of improvement in language acquisition can be claimed for students who have taken courses on this system. The approximately 1000 students who have taken these courses so far have shown an average increase of $35 \%$ in listening comprehension, $24 \%$ in grammatical accuracy and $10 \%$ in vocabulary acquisition over an average period of 10 weeks, based on standardized pre- and post-tests.

\section{References}

Alley, L. and Jansak, K. (2001) Ten keys to quality assurance and assessment in online learning - Online document: http:/ / www.worldclassstrategies.com/ papers / keys.htm.

Bambrough, P. (1994) Simulations in English Teaching. Buckingham: Open University Press.

Barnett, L. (1993) Teacher off: Computer technology, guidance and self-access. System 21 (3), 295-304.

Biggs, J. and Telfer, R. (1987) The Process of Learning. Sydney: Prentice Hall Australia.

Cheng, J (1999, Oct 1) Opening the window of opportunity. South China Morning Post, A22-A23.

Crookall, D. and R.L. Oxford (eds) (1990) Simulation, Gaming, and Language Learning. New York: Newbury House.

Duquette, L., Renie, D. and Laurier, M. (1998) The evaluation of vocabulary acquisition when learning French as a second language in a multimedia environment. Computer Assisted Language Learning 11 (1), 3-34.

Ferris, D. (1995) Student reactions to teacher response in multiple-draft composition classrooms. TESOL Quarterly 29 (1), 33-53.

Jensen, B. (2003) The history and future of course authoring technologies - Online document: http: / / www.trinity.edu / rjensen/290wp/290wp.htm.

Johns, T. and King, P. (eds) (1991) Classroom Concordancing. Birmingham: Birmingham University.

Jones, K. (1985) Designing Your Own Simulations. London: Methuen \& Co. Ltd. 
Kluge D. and Taylor, M. (2000) Boosting speaking fluency through partner taping. The Internet TESL Journal, VI (2) - Online document: http://iteslj.org/Techniques/Kluge-PartnerTaping.html.

Ladousse, G.P. (1987) Role Play. Hong Kong: Oxford University Press.

Li, M-S. (1999) Perceptions of the place of expatriate English language teachers in China. PhD thesis, La Trobe University - Online document: http: / / my.glasscity. net/ xiong/tic/li.html.

Milton, J. (2001) Elements of a Written Interlanguage: Institutional Influences on the Acquisition of English by Hong Kong Chinese Students. Hong Kong: The Hong Kong University of Science and Technology.

Nikolova, O. (2002) Effects of students' participation in authoring of multimedia materials on student acquisition of vocabulary. $6(1), 100-22$.

Oller, J.W. Jr. (1993) Reasons why some methods work. In J.W. Oller, Jr (ed.). Methods that Work (pp. 374-85). Boston, MA: Heinle and Heinle.

Paris, S.G. (1995) Why learner-centered assessment is better than high-stakes testing. In N.M. Lambert and B.L. McComb (eds) How Students Learn: Reforming Schools through Learner-centered Education (pp. 189-209). Washington, DC: American Psychological Association.

Perkins, K. (1983) On the use of composition scoring techniques, objective measures, and objective tests to evaluate ESL writing ability. TESOL Quarterly 17 (4), 651-71.

Ryokai, K., Vaucelle, C. and Cassell, J. (2003) Virtual peers as partners in storytelling and literacy learning. Journal of Computer-Assisted Learning 19 (2), 195-208.

Rukeyser, M. (1960) The Speed of Darkness. New York: Random House.

Scarcella, R. and Crookall, D. (1990) Simulation/gaming and language acquisition. In D. Crookall and R.L. Oxford (eds) Simulation, Gaming, and Language Learning (pp. 223-30). New York: Newbury House.

Schneider, P. (1997) Using Pair Taping. The Internet TESL Journal, III (2) - Online document: http: / / iteslj.org/.

Sinclair, J. (1991) Corpus, Concordance and Collocation. Oxford: Oxford University Press.

Warschauer, M. (1999) Electronic Literacies: Language, Culture, and Power in Online Education. Mahwah, NJ: Lawrence Erlbaum Associates.

Wilde, O. (1890) Reprinted in R. Ellmann (ed.) (1998) The Artist as Critic: Critical Writings of Oscar Wilde (p. 349). New York: Random House.

Zeng, K. (1999) Dragon Gate: Competitive Examinations and their Consequences. London: Cassell. 